\title{
Tropical Forests Mapping of Bioko Island Using Remote Sensing Techniques
}

\author{
Mohamed Elhag \\ Department of Hydrology and Water Resources Management, Faculty of Meteorology, \\ Environment \& Arid Land Agriculture, King Abdulaziz University \\ Jeddah, 21589. Kingdom of Saudi Arabia
}

melhag@kau.edu.sa

\begin{abstract}
Forest sustainable management requires basically adequate vegetation mapping. Remote sensing techniques delivers reliable classification scheme of medicinal species Prunus africana located in Bioko Island -Equatorial Guinea. Prunus africana sustainable management relies principally on the population's quantification of the sustainable trade volume. Unsupervised and supervised image classifications techniques were implemented on Landsat OLI-8 (Operational Land Imager-8) to produce P. africana thematic maps on Bioko. Primarily, Support Vector Machine classification algorithm realized overall accuracy of $82.01 \%$, with kappa coefficient of 0.79 . Forests misclassification was mainly confined between two interconnected classes of Guineo-Congolian/ Afromontane forest classes and lowland forest classes. Therefore an extra rule of determent altitude $(>1400 \mathrm{~m})$ was added to the classification decision rule to improve the classification accuracies to be estimated as overall accuracy of $80.01 \%$ and a kappa coefficient of 0.81 . Regular ground truth data collection from nine transects found that both of $P$. africana and Schefflera sp. were dominantly the two arboreal species located in Bioko's forests. Thematic classification maps illustrated in the conducted research is an essential data for the sustainable management of $P$. africana bark extraction. These results may also be valuable for various future studies ranging from primate research to genetic variation of $P$. africana on Bioko Island.
\end{abstract}

Keywords: Afromontane forests, Landsat OLI-8, Non-Timber Forest Products, Prunus africana, Tropical forests.

\section{Introduction}

The tropical ecosystems are composed of mosaics of forest of different sizes and in distinct phases of natural regeneration (Whitmore, 1991; Martinez-Ramos, 1994). Many explanations of the high diversity of species in the tropical systems have been concentrated in the study of natural disturbances and the generation of heterogeneous conditions which facilitate the dispersion, germination, establishment and growth of seedlings in the clear zones beneath the canopy of the forest (Ricklefs, 1987). The species of the study: P. africana (Hook, f.) Walkman (= Pygeum africanum), enjoys its 
greatest distribution in African and Malagasy orests found at higher altitudes, above the Guineo-Congolian rain forests.

On nearly all African mountains, the forest diminishes in structure and complexity from the lower slopes to the summit, yet this regularity is modified by local features of aspect, exposure, incidence of frost, depth of soil, and by overall patterns of climate which depend on the size and configuration of the mountain in relation to distance from the sea (White, 1983).

P. africana is a forest species of great importance to African traditional medicine for its use in the treatment of chest pains, malaria, and feverish symptoms. Commercial exploitation of the species began for its timber at the beginning of the $20^{\text {th }}$ century in South Africa and Kenya. In 1966, a bark extract from the species was patented as a treatment for prostate ailments (Cunningham and Mbenkum, 1993), with bark extraction beginning in Cameroon in 1972.

The market for $P$. africana is global. The exploitation of its bark has severely reduced natural populations of $P$. africana. In 2000, the international consumption of $P$. africana bark was estimated at more than $4000 \mathrm{t}$, of which Cameroon produced two thirds (Toney et al, 2000). Large-scale exploitation of $P$. africana bark has diversified toward other countries such as Madagascar, Democratic Republic Congo, and Kenya.

The Mount Cameroon region and the mountain ecosystems of Bioko have been grouped together to form a part of the Afromontane floristic region (White, 1983). The Afromontane habitats are isolated from each other, as is the case on the volcanic island of Bioko which belongs to the Gulf of Guinea Islands group (composed of Sao Tomé, Principe and Annobón). P. africana exists on
Sao Tomé and within three zones on Bioko: Pico Basilé, Caldera de Luba, and Lago Biao (Thibaut Kaptué, et al., 2011).

P. africana is at risk of unsustainable bark extraction or being felled for both bark and timber (Zafra-Calvo, et al., 2010). Every population lost to forest clearance or unsustainable bark harvesting reduces the genetic diversity of this species and negatively affects surrounding flora and fauna. Previous study of diversity among the geographically disjunct $P$. africana populations considers that diversity and differences exist among populations of $P$. africana (Simons and Leakey, 2004). Crown dieback and eventual tree death due to improper bark harvesting techniques have been documented on Bioko (Sunderland and Tako, 1999). It is not certain that these trees will recover and reproduce the bark taken during these first extractions. Improper bark extraction continues and existing populations have remained both unqualified and unmapped (Bussmann, 2006 and Zafra-Calvo, et al., 2010).

Changes in species composition and stand structure are accompanied by similar changes in spectral properties. Successional status in tropical ecosystems, characterized by species composition, biomass, and distribution of heights and diameters has been used to indicate relationships between forest successional stages and spectral properties of Landsat TM data (Vieira, et al., 2003). The ability to identify different regenerating forest classes was investigated with Landsat TM data at a test site near Manaus, Brazil (Foody and Hill, 1996).

Tropical forest types differ in species composition, canopy height, and understory vegetation. Some of these studies have tried to classify forests among stand age, while others have relied on species composition, edaphic conditions (Foody and Hill, 1996) or 
hyperspectral sensors (Thenkabail, et al., 2003) and presented better results. In this study, field observations concerning ecosystem type, species composition, and distributions of heights and diameters will be used to classify the forest types of Bioko.

Authors have stated that the use of the near (NIR) and mid infrared (MIR) bands improves the accuracy of vegetation mapping (Salovaara, et al., 2005; Thenkabail, et al, 2004). Young secondary vegetation typically shows the highest reflectance in Landsat band 4 , with other more mature forests reflecting relatively less. The MIR band of the ETM+ improved the strength of regressions used to explain variation in stem density and basal area of rainforests (Thenkabail, et al., 2003). This approach was used in the detection of floristic structure across different topographic and moisture gradients in a mixed species Central African forest.

The aim of this study is to first develop a detailed vegetation map of Bioko (Equatorial Guinea) based on the classification of Landsat OLI-8 imagery, and then a second vegetation map detailing Afromontane vegetation. The Afromontane vegetation map will be created by combining data collected from systematic inventory plots with remote sensing techniques.

\section{Materials and Methods}

\subsection{Study area}

Bioko Island (3"48'-3" 12"N; 8"25' 8"57'E) is located in the Gulf of Guinea, $32 \mathrm{~km}$ from the Cameroon coast. The island (Figure 1) is rectangular in shape $(69 \times 32 \mathrm{~km})$ and has an area of $2017 \mathrm{~km}^{2}$. Geologically, Bioko is a part of the African continental platform. The island is divided into two administrative zones:
Bioko Norte and Bioko Sur. The islands of the Gulf of Guinea (Bioko, Principe, Sao Tomé, and Annabón) form part of the Cameroon line of volcanoes. These volcanoes, including Mt. Cameroon and its highlands, were formed as a result of volcanic eruptions during the Lower Tertiary and early Quaternary period. Geological studies have suggested that these volcanoes developed along a fracture stretching NE-SW from Mounts Kupe and Manenguba (Cameroon) all the way to $\mathrm{St}$ Helena Island located in the South Atlantic (Juste and Fa, 1994). The island is composed of two main volcanic massifs: Pico Basilé $(3011 \mathrm{~m})$ in the north, and the southern volcanic peaks of Pico Biao (2009 m) and Caldera de Luba (2261 m). Pico Basilé, having developed from basaltic lava flows, presents a gentle, yet steady incline on the north-eastern and south-western slopes. Travelling northwest from the peak lies the $5 \mathrm{~km}$ wide Caldera de Bonyoma which offers a change in altitude of over $1000 \mathrm{~m}$ within a horizontal distance of less than $1 \mathrm{~km}$. A series of cinder cones follow this depression, along with other such cones found on the lower slopes of P. Basilé. Three eruptions have taken place on the south eastern flank of P. Basilé, in 1898, 1903, and 1923 (Global Volcanism Program, Smithsonian Institution, 2005). Fa (1991) reports latent volcanic activity on Bioko, with eruptions in 1880 and 1900 and seismic activity noted in 1922. A central depression on Bioko separates the volcanic massif of P. Basilé from the southern massif dominated by the Caldera de Luba $(2261 \mathrm{~m})$. The caldera has a diameter of approximately $5 \mathrm{~km}$. The rivers on the island drain radially from the main volcanic massifs of Pico Basilé, Biao and the Caldera de Luba. The river Tiburones descends the southern slopes of P. Basilé and empties into the bay of Luba. 


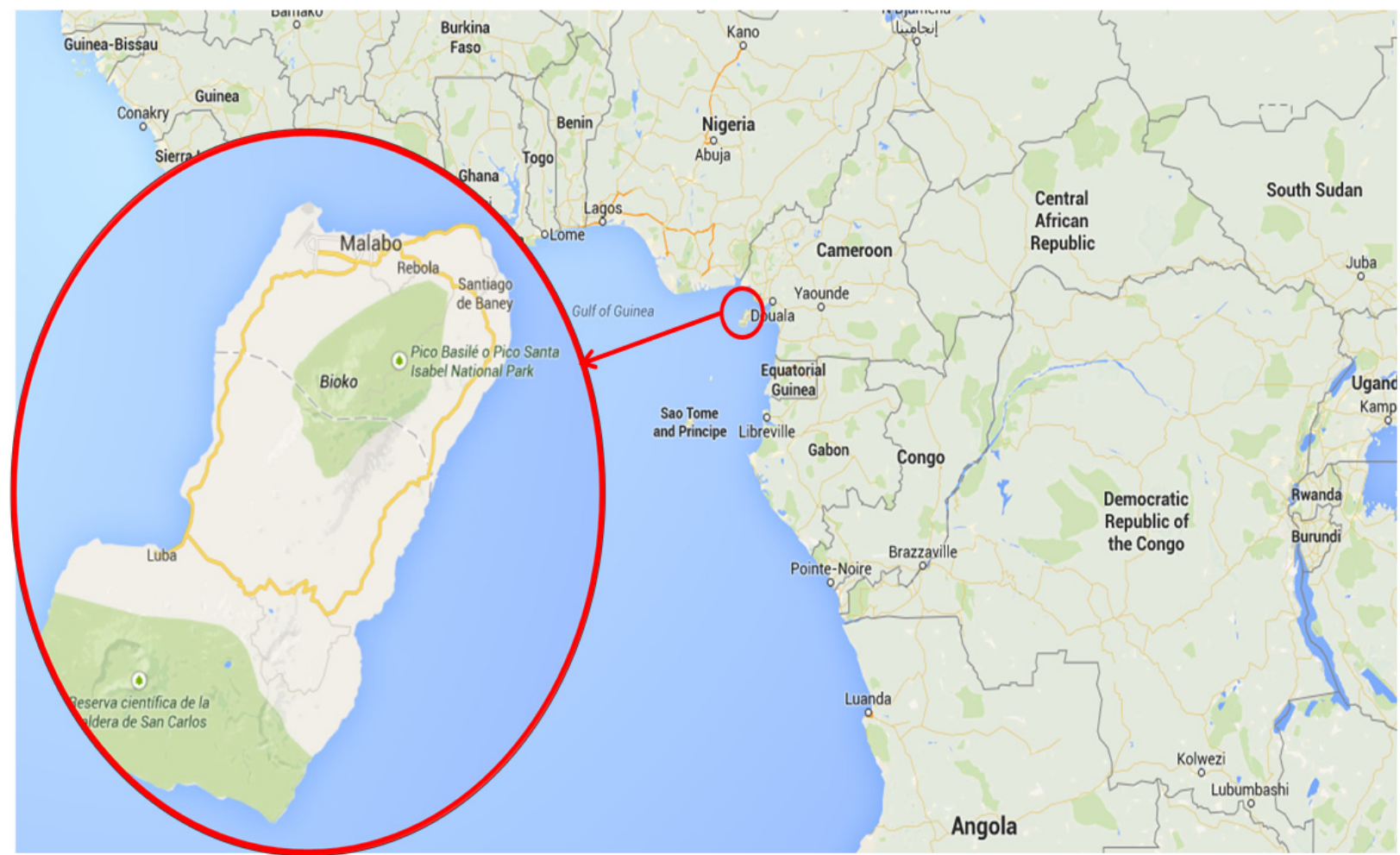

Fig. 1. Study area location.

\subsection{Sampling design and data collection}

The potential distribution of $P$. africana lies within an area of 31,969 hectares in the island of Bioko. 16,000 hectares are within the National Park of P. Basile and the rest are in the zones of Moka and the Western region of the Caldera de Luba. No P. africana were found below $1400 \mathrm{~m}$, as a result it was decided that the study zone to be restricted between $1400 \mathrm{~m}$ and $2400 \mathrm{~m}$ altitude. Extraction of $P$. africana bark in the Moka region takes place in two distinct areas: in secondary forest west of Moka village and around Lago Biao.

The inventory design selected was a stratified inventory with systematic collection points every 10 minutes (approximately 100 meters) following already existing trails of extraction. In Pico Basilé and Lago Biao, the only accessible entrances into the forest are trails maintained by hunters and those who extract $P$. africana bark, and those trails were selected as transects for study of P. africana.

Data collected from systematic inventory plots was used to validate the supervised classification maps and to characterize forests with the presence of $P$. africana.

\subsection{Image processing}

The following methodology will recount the steps conducted during the production of the thematic maps of vegetation types found on Bioko. These maps will be based on supervised classifications of Bioko vegetative cover. The supervised classification was created through bibliographic references, field observations, and in part from the unsupervised classification derived from satellite imagery. Another forthcoming result based on forest inventories carried out on Pico Basilé, village of Moka, and Lago Biao will 
yield a description of the forests which contain P. africana.

\subsubsection{Image preprocessing}

Digital sensors mounted on satellites record the intensity of electromagnetic radiation from each spot viewed on the Earth's surface as a digital number (DN). A major characteristic of such sensors is that they record the DN for several different wavelengths of electromagnetic energy. The exact range of DN that a sensor utilizes depends on the sensor used, Boyd and Duane 2001.

Radiance had to be converted to exatmospheric reflectance. Reflectance does not have units and is measured on a scale from 0 to 1 (or $0-100 \%$ ). In order to achieve this conversion, a standardization equation was applied to every pixel in the image. This equation converts the image's digital numbers (DN, or voltage measurements) to at-sensor radiance and computes at-sensor reflectance while normalizing solar elevation angle, Richards, 1993:

$\rho_{P}=\frac{\pi * L_{\lambda} * d^{2}}{E S U N_{\lambda} * \cos \theta_{S}}$

Where:

$\rho_{P}$ is the at-satellite exo-atmospheric reflectance,

$L_{\lambda}$ is the radiance $\left(\mathrm{W} \mathrm{m}^{-2} \mathrm{sr}^{-1} \mu \mathrm{m}^{-1}\right)$

$\mathrm{d}$ is the earth to sun distance in astronomic units at the acquisition date

$E S U N_{\lambda}$ is the mean solar exoatmospheric irradiance ( $\left(\mathrm{W} \mathrm{m}^{-2} \mathrm{sr}^{-1} \mu \mathrm{m}^{-1}\right)$

$\theta_{S}$ is the solar zenith angle in degrees

\subsubsection{Unsupervised classification}

An unsupervised classification was the first step in understanding Bioko's vegetation and land cover. The unsupervised classification is a method in which the pixels in an image are assigned to spectral classes without the user being aware of the existence or names of these classes (Richards, 1993). This method is most useful for determining spectral class composition prior to detailed analysis through supervised classification.

The unsupervised classification performed here was created using the ISODATA module from Erdas 2014 software. The classification of satellite images generally involves the assignment of a particular class value to every pixel. ISODATA classification is referred as quantitative analysis because of its ability to identify pixels according to numerical properties in order to minimize the Mean Squared Error (MSE). Basically, the unsupervised classification is a method by which the labels may be attached to pixels in view of their spectral character (Jensen, 1996):

$M S E=\frac{\sum_{\forall x}[x-C(x)]^{2}}{(N-c) b}$

Where

$N$ is the number of pixels, $c$ indicates the number of clusters,

$b$ is the number of spectral bands

\subsubsection{Supervised classification}

The supervised classification is the procedure most often used for quantitative analysis of remote sensing image data. One of the most important factors regarding supervised classification is the selection of an appropriate algorithm which will label pixels according to ground cover types, or in this case, vegetation classes. The steps for supervised classification are summarized by Richards (1993).

Georeferenced ground information used for supervised classification training areas were of 
three types: georeferenced observations, $P$. africana observations, and systematic inventory field plots. These observations served as representative pixels for the training areas of the supervised classifications. Systematic field inventories and $P$. africana observations took place above the $1400 \mathrm{~m}$ altitudinal limit, which was considered the $P$. africana field work study zone.

Because of the complexity of vegetation cover of Bioko, the reflectance ranges of the land cover classes at times overlapped. As a result, it was decided that Support Vector Machine classification would be more suitable (Elhag, et al., 2013). With this classifier, training data is used only to distinguish the categories upon margin maximization of a decision surface between the categories based on sigmoidal function equation (Richards, 1993):

$K\left(x_{i}, x_{j}\right)=\tanh \left(g x_{i}^{T} x_{j}+r\right)$

Where:

$g$ is the gamma term in the kernel function for all kernel types except linear

$r$ is the bias term in the kernel function for the polynomial and sigmoid kernels.

\subsection{Accuracy assessment}

An error matrix was determined and the producer's Accuracy (a measure of omission error), user's Accuracy (a measure of commission error) and the kappa coefficient of agreement were calculated for each class and for both supervised classifications. The method is a simple cross-tabulation of the mapped class label against that observed in the ground or reference data for a sample of cases at specified locations (Foody, 2002).

In digital image analysis is the assessment of the accuracy of the computer derived classification results is the final step. Producers, users and Overall accuracy were derived from a Matrix. These results often articulated in plane form, known as a confusion matrix. The Kappa examination is distinct multivariate method used in accuracy assessment to specify statically whether one error matrix is significantly different to another (Cohen, 1960). The accuracy assessment was carried out following Congalton and Mead (1983) and Congalton (1991) to estimate $K_{\text {hat }}$ for different the employed classification algorithms:

$K_{h a t}=\frac{N \sum_{i=1}^{r} x_{i i}-\sum_{i=1}^{r}\left(x_{i j} \times x_{j i}\right)}{N^{2}-\sum_{i=1}^{r}\left(x_{i j} \times x_{j i}\right)} \quad$ Eq. 7

Where

$r$ is number of rows in the error matrix;

$x_{i i}$ is number of observations in row ${ }_{i}$ and

column $_{i}$ (the diagonal cells);

$x_{i+}$ is total observations of row $i$;

$x_{+1}$ is total observations of column $i$

$N$ is total of observations in the matrix

$K_{\text {hat }}$ value of 0.80 and higher indicates strong agreement and a value between 0.40 and 0.80 indicates moderate agreement. Accuracy assessment using the kappa coefficient was performed on both of the thematic maps produced through the supervised classification.

\section{Results}

\subsection{Unsupervised classification}

The unsupervised cluster classification of 14 classes was named and analyzed (Figure 2). Classes described consist of coastal evergreen forest (HGC), primary lowland forest (GCPRIM), corresponding lowland rain forest secondary formations depending on date and type of anthropogenic disturbance (LLDEG, 
GCCC, OSECGC, YSECGC, CULT) mixed lowland and Afromontane forests and corresponding secondary formations (MIXGC, SECMIX), Afromontane forests and corresponding secondary formations (UAFR, AFRH, SECAFR, SECGRAS), and finally higher altitude formations of ericaceous shrub land (ERIC).

Table 1 displays the spectral relationships by indicating the Euclidean distance between classes. This Euclidean distance was based on average reflectance values per class for Landsat bands 2 through 5 and band 7. The unsupervised classification spectral separability measure shows that the HGC vegetation class had the highest separability value, making it the most unique class. It should also be noted that the SECGRAS class may be considered as having a high separability value.

Figure 3 shows the results of this classification. Vegetation types presented consist of classes recognized through the unsupervised classification and classes recognized during field work. Vegetation classes generally follow an altitudinal distribution with corresponding secondary formations included. Low altitude vegetation classes include primary rain forest (GCPRIM) along with secondary formations which may be attributed to different anthropogenic influences such as areas surrounding rural populations (SECRURAL), areas currently or in the past used for agricultural purposes (OSECGC, GCCC) and natural resources extraction (GCDEG).

\subsection{Supervised classification}

Table 2 is a description of training areas used in supervised classification of Bioko. 15 georeferenced observation points per class were used as training areas on which to base class spectral signatures. 30 points per class were reserved for accuracy assessment. Descriptions of the individual classes are composed of notes taken during field observations on Bioko. Bibliographic references combined with analysis of the unsupervised classification have assisted in the description of inaccessible sites.

\subsection{Accuracy assessment}

Accuracy assessment (Table 3) was performed in order to evaluate the classification results and the overall accuracy for the classification process. A global accuracy of $82.01 \%$ was achieved with a kappa coefficient of 0.79 . Individual class accuracies were moderately good for classes within the Afromontane vegetation zone (AFALP, ERIC, PAST, SECAFR, ARAL). Distinct patches of primary forest and areas subject to timber exploitation (GCPRIM, GCDEG) achieved high classification accuracies. Lowland secondary vegetation classes (SECRURAL and GCCC) were often misclassified with mixed forest (MIXGC) and Afromontane forest humid type.

The classes with the lowest average separability included GCCC and MIXGC, both of which contain affinities with other vegetation classes. Based on the results of the unsupervised classification it was decided that some classes would be merged for the supervised classification. This was done with the YSECGC and CULT, whose separability values indicated strong spectral similarities between these classes. 
Table 1. Spectral Separability of Land Cover Classes derived from Cluster Unsupervised Classification of Bioko vegetation.

\begin{tabular}{|c|c|c|c|c|c|c|c|c|c|c|c|c|c|c|}
\hline $\begin{array}{l}\text { Land Cover } \\
\text { Class }\end{array}$ & HGC & GCPRIM & ERIC & UAFR & LLDEG & AFRH & GCCC & OSECGC & YSECGC & MIXGC & SECAFR & SECMIX & CULT & SECGRAS \\
\hline HGC & 0.000 & 0.042 & 0.060 & 0.095 & 0.065 & 0.076 & 0.085 & 0.082 & 01.04 & 0.101 & 0.121 & 0.120 & 0.126 & 0.144 \\
\hline GCPRIM & 0.042 & 0.000 & 0.035 & 0.062 & 0.023 & 0.037 & 0.044 & 0.042 & 0.063 & 0.061 & 0.082 & 0.079 & 0.085 & 0.103 \\
\hline ERIC & 0.060 & 0.035 & 0.000 & 0.039 & 0.039 & 0.031 & 0.051 & 0.058 & 0.071 & 0.058 & 0.071 & 0.078 & 0.092 & 0.097 \\
\hline UAFR & 0.095 & 0.062 & 0.039 & 0.000 & 0.050 & 0.030 & 0.043 & 0.058 & 0.058 & 0.036 & 0.036 & 0.053 & 0.074 & 0.065 \\
\hline LLDEG & 0.065 & 0.023 & 0.039 & 0.050 & 0.000 & 0.021 & 0.022 & 0.020 & 0.040 & 0.039 & 0.061 & 0.056 & 0.062 & 0.081 \\
\hline AFRH & 0.076 & 0.037 & 0.031 & 0.030 & 0.021 & 0.000 & 0.023 & 0.032 & 0.041 & 0.029 & 0.047 & 0.049 & 0.062 & 0.070 \\
\hline GCCC & 0.085 & 0.044 & 0.051 & 0.043 & 0.022 & 0.023 & 0.000 & 0.018 & 0.023 & 0.019 & 0.043 & 0.035 & 0.045 & 0.061 \\
\hline OSECGC & 0.082 & 0.042 & 0.058 & 0.058 & 0.020 & 0.032 & 0.018 & 0.000 & 0.023 & 0.033 & 0.057 & 0.044 & 0.044 & 0.070 \\
\hline YSECGC & 0.104 & 0.063 & 0.071 & 0.058 & 0.040 & 0.041 & 0.023 & 0.023 & 0.000 & 0.023 & 0.043 & 0.023 & 0.023 & 0.049 \\
\hline MIXGC & 0.101 & 0.061 & 0.058 & 0.036 & 0.039 & 0.029 & 0.019 & 0.033 & 0.023 & 0.000 & 0.025 & 0.020 & 0.038 & 0.043 \\
\hline SECAFR & 0.121 & 0.082 & 0.071 & 0.036 & 0.061 & 0.047 & 0.043 & 0.057 & 0.043 & 0.025 & 0.000 & 0.025 & 0.048 & 0.029 \\
\hline SECMIX & 0.120 & 0.079 & 0.078 & 0.053 & 0.056 & 0.049 & 0.035 & 0.044 & 0.023 & 0.020 & 0.025 & 0.000 & 0.024 & 0.027 \\
\hline CULT & 0.126 & 0.085 & 0.092 & 0.074 & 0.062 & 0.062 & 0.045 & 0.044 & 0.023 & 0.038 & 0.048 & 0.024 & 0.000 & 0.039 \\
\hline SECGRAS & 0.144 & 0.103 & 0.097 & 0.065 & 0.081 & 0.070 & 0.061 & 0.070 & 0.049 & 0.043 & 0.029 & 0.027 & 0.039 & 0.000 \\
\hline $\begin{array}{l}\text { Av. Class } \\
\text { Separability }\end{array}$ & 0.078 & 0.054 & 0.056 & 0.050 & 0.041 & 0.039 & 0.036 & 0.042 & 0.042 & 0.038 & 0.049 & 0.045 & 0.054 & 0.063 \\
\hline $\begin{array}{c}\text { Global } \\
\text { Separability }\end{array}$ & 0.049 & & & & & & & & & & & & & \\
\hline
\end{tabular}

MIXGC: Guineo-Congolian rain forest with Afromontane elements, AFRH: Afromontane forest humid type, AFALP: Afro-alpine vegetation, ERIC: Ericaceous shrubland, PAST: Pastures, SECAFR: Secondary Afromontane forest, SECGRAS: Secondary Afromontane grassland, ARAL: Afromontane forest Araliaceae type, GCDEG: Guineo-Congolian rain forest degraded, SECRURAL: Secondary rural complex, OSECGC: Old secondary Guineo-Congolian rain forest, GCPRIM: Primary Guineo-Congolian rain forest, HGC: Hygrophilous coastal evergreen rain forest, GCCC: Degraded Guineo-Congolian forest mixed with cacao and palm. 
Table 2. Training areas used in supervised classification of Bioko land cover.

\begin{tabular}{ccc}
\hline $\begin{array}{c}\text { Land Cover } \\
\text { Class* }\end{array}$ & $\begin{array}{c}\text { Number of } \\
\text { observ./class }\end{array}$ & Training area description \\
\hline
\end{tabular}

\section{MIXGC}

AFRH

AFLAP

ERIC

PAST

SECAFR

SECGRAS

ARAL

GCDEG

SECRURAL

OSECGC

GCPRIM

HGC

GCCC
Areas subjected to timber extraction, particularly on the southern slopes of Bioko around the village of Ureka.

Secondary forest intermixed with rural settlements, gardens, and agricultural production.

Mature Guineo-Congolian secondary forest with tall canopy up to $40 \mathrm{~m}$, very dense understory.

Remaining primary lowland forest, monsoon forest of southern Bioko, extremely dense rain forest, epiphytes, lianas.

Coastal forest with coconut palms, and Cacsalpinaceae. abandoned in many parts of Bioko.

*MIXGC: Guineo-Congolian rain forest with Afromontane elements, AFRH: Afromontane forest humid type, AFALP: Afro-alpine vegetation, ERIC: Ericaceous shrubland, PAST: Pastures, SECAFR: Secondary Afromontane forest, SECGRAS: Secondary Afromontane grassland, ARAL: Afromontane forest Araliaceae type, GCDEG: Guineo-Congolian rain forest degraded, SECRURAL: Secondary rural complex, OSECGC: Old secondary Guineo-Congolian rain forest, GCPRIM: Primary Guineo-Congolian rain forest, HGC: Hygrophilous coastal evergreen rain forest, GCCC: Degraded Guineo-Congolian forest mixed with cacao and palm. 
Table 3. Confusion Matrix from supervised classification of Bioko vegetation.

\begin{tabular}{|c|c|c|c|c|c|c|c|c|c|c|c|c|c|c|c|c|}
\hline \multirow[b]{2}{*}{ Actual Class } & \multicolumn{15}{|c|}{ Predicted class } & \multirow{2}{*}{ Producer's Accuracy } \\
\hline & MIXGC & AFRH & AFLAI & PERIC & PAST & SECAFR & SECGRAS & ARAI & GCDEC & SECRURAL & OSECGC & GCPRIM & HGC & GCCC & $\Sigma$ & \\
\hline MIXGC & 21 & 0 & 0 & 0 & 0 & 2 & 1 & 0 & 1 & 5 & 0 & 0 & 0 & 0 & 30 & 70.00 \\
\hline AFRH & 5 & 6 & 0 & 0 & 0 & 6 & 1 & 0 & 0 & 11 & 0 & 1 & 0 & 0 & 30 & 20.00 \\
\hline AFLAP & 0 & 1 & 17 & 10 & 1 & 0 & 0 & 0 & 0 & 0 & 0 & 0 & 0 & 0 & 30 & 58.62 \\
\hline ERIC & 0 & 0 & 0 & 23 & 0 & 0 & 0 & 4 & 0 & 0 & 0 & 3 & 0 & 0 & 30 & 76.67 \\
\hline PAST & 0 & 0 & 0 & 0 & 30 & 0 & 0 & 0 & 0 & 0 & 0 & 0 & 0 & 0 & 30 & 100 \\
\hline SECAFR & 0 & 0 & 0 & 0 & 0 & 25 & 4 & 1 & 0 & 0 & 0 & 0 & 0 & 0 & 30 & 83.33 \\
\hline SECGRAS & 1 & 2 & 0 & 0 & 7 & 2 & 17 & 0 & 0 & 0 & 0 & 0 & 0 & 0 & 30 & 58.62 \\
\hline ARAL & 1 & 0 & 0 & 0 & 0 & 1 & 0 & 28 & 0 & 0 & 0 & 0 & 0 & 0 & 30 & 93.33 \\
\hline GCDEG & 0 & 1 & 0 & 0 & 0 & 0 & 0 & 0 & 29 & 0 & 0 & 0 & 0 & 0 & 30 & 96.67 \\
\hline SECRURAL & 4 & 0 & 0 & 0 & 0 & 1 & 2 & 0 & 0 & 17 & 3 & 0 & 0 & 3 & 30 & 56.67 \\
\hline OSECGC & 0 & 0 & 0 & 0 & 0 & 0 & 0 & 0 & 5 & 1 & 16 & 1 & 0 & 7 & 30 & 53.33 \\
\hline GCPRIM & 0 & 0 & 0 & 0 & 0 & 0 & 0 & 0 & 1 & 0 & 0 & 29 & 0 & 0 & 30 & 96.67 \\
\hline HGC & 0 & 0 & 0 & 0 & 0 & 0 & 0 & 0 & 0 & 0 & 0 & 0 & 30 & 0 & 30 & 100 \\
\hline GCCC & 12 & 1 & 0 & 0 & 0 & 0 & 1 & 2 & 0 & 1 & 0 & 0 & 0 & 13 & 30 & 43.33 \\
\hline$\Sigma$ & 44 & 11 & 17 & 33 & 38 & 37 & 26 & 35 & 36 & 35 & 19 & 34 & 30 & 23 & & \\
\hline User's Accuracy & \begin{tabular}{l|l} 
& 47.73
\end{tabular} & 54.55 & 100 & 69.70 & 78.95 & 67.57 & 65.38 & 80.00 & 80.56 & 48.57 & 84.21 & 85.29 & 100 & 56.52 & & \\
\hline
\end{tabular}

Overall percentage correct allocation was $82.01 \%$, the kappa coefficient was 0.79 . The Global Producer's Accuracy was $81.95 \%$ and the Global User's Accuracy was $82.79 \%$.

MIXGC: Guineo-Congolian rain forest with Afromontane elements, AFRH: Afromontane forest humid type, AFALP: Afro-alpine vegetation, ERIC: Ericaceous shrubland, PAST: Pastures, SECAFR: Secondary Afromontane forest, SECGRAS: Secondary Afromontane grassland, ARAL: Afromontane forest Araliaceae type, GCDEG: Guineo-Congolian rain forest degraded, SECRURAL: Secondary rural complex, OSECGC: Old secondary Guineo-Congolian rain forest, GCPRIM: Primary Guineo-Congolian rain forest, HGC: Hygrophilous coastal evergreen rain forest, GCCC: Degraded Guineo-Congolian forest mixed with cacao and palm. 

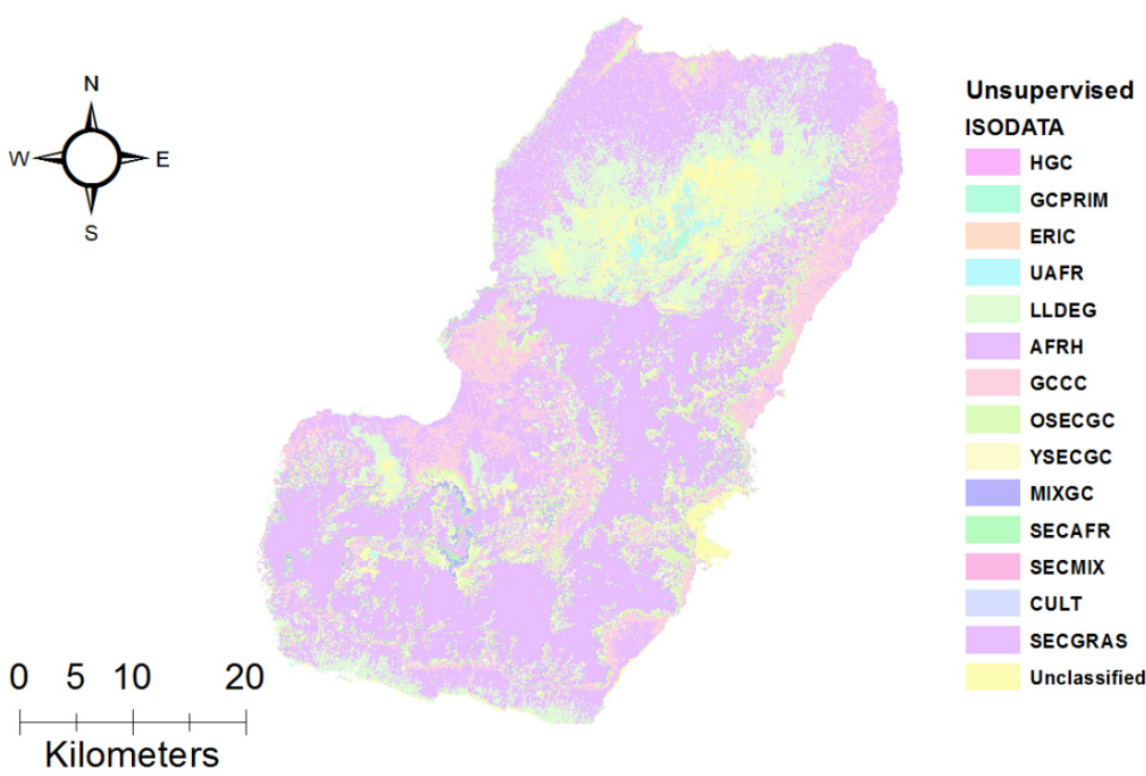

Fig. 2. ISODATA unsupervised classification of Bioko Island.
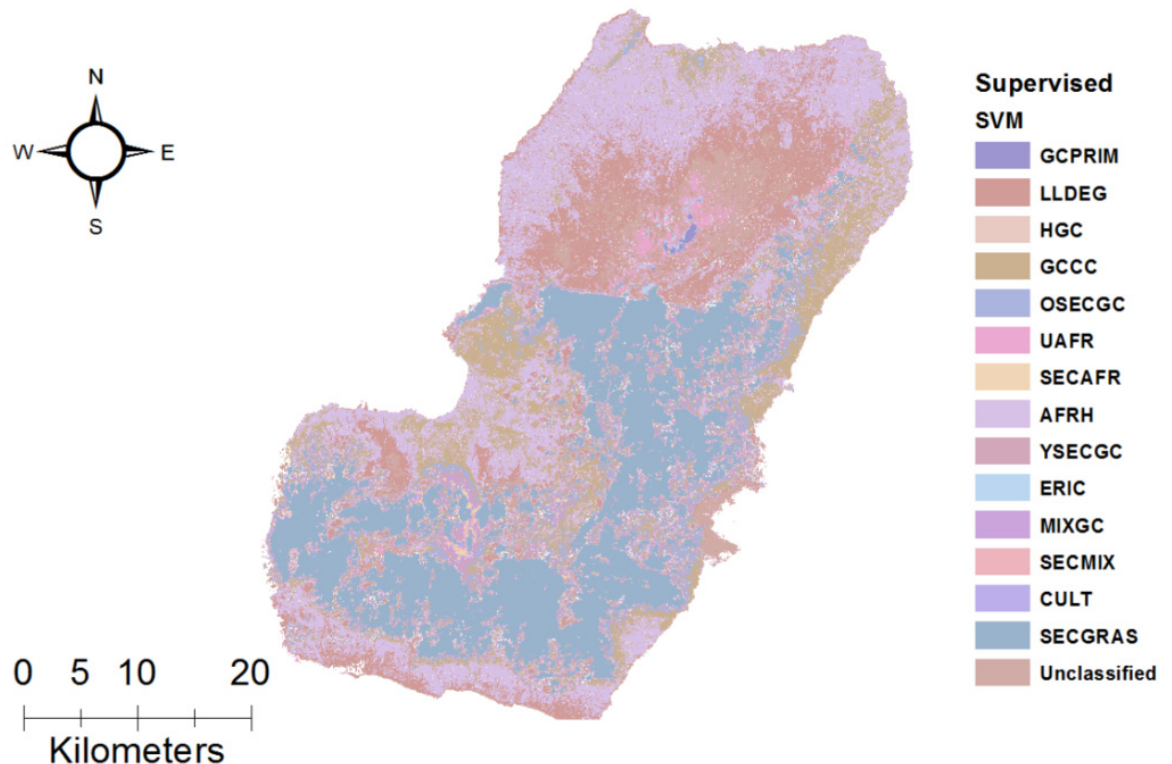

Fig. 3. SVM supervised classification of Bioko Island.

MIXGC: Guineo-Congolian rain forest with Afromontane elements, AFRH: Afromontane forest humid type, AFALP: Afro-alpine vegetation, ERIC: Ericaceous shrubland, PAST: Pastures, SECAFR: Secondary Afromontane forest, SECGRAS: Secondary Afromontane grassland, ARAL: Afromontane forest Araliaceae type, GCDEG: Guineo-Congolian rain forest degraded, SECRURAL: Secondary rural complex, OSECGC: Old secondary Guineo-Congolian rain forest, GCPRIM: Primary Guineo-Congolian rain forest, HGC: Hygrophilous coastal evergreen rain forest, GCCC: Degraded Guineo-Congolian forest mixed with cacao and palm. 


\section{Discussion}

Analysis of remotely sensed data aided by field inventories is commonly used to classify land cover. In this case, the identification of forest types and the species composition of African tropical forests were undertaken to produce thematic maps. These thematic maps along with the description of such classes contribute toward the assessment of natural resources located within the forests of Bioko.

Firstly, unsupervised classification was produced to investigate the spectral properties of Bioko land cover. This classification served to provide preliminary information concerning the reflectance values of Guineo-Congolian and Afromontane forest. Collection of forest measurements and species composition from systematic inventory plots within various montane forest types on Bioko was essential for an accurate classification. A relationship between forest types and pixel reflectance had to be established in order to generate a thematic map with high user accuracy. Similar classification techniques have been used to show that changes in species composition and stand structure are accompanied by similar changes in the spectral properties of tropical forest Vieira, et al., 2003.

Successful combination of spectral data from Landsat OLI-8 imagery with field measurement of forest attributes indicates the continuing potential for applications of remote sensing to the study of tropical forests. In this work and other studies, there are clear indications that carefully selected narrow portions of the wavebands, spread across the visible, near-infrared, and mid-infrared (400$2500 \mathrm{~nm}$ ) will be required for continued improvement in the study of forest structure (basal area, stem density) and species compositions, Vieira, et al, 2003; Thenkabail, et al, 2003.
Results of the two supervised classifications indicate agreement between field observations and remotely sensed data of Bioko Island. Among the Afromontane forest types presented exist structural differences which may be observed through species composition and physiographic variables collected during field sampling. Further, the combination of data collected on Bioko with the results of the field inventories indicate the diverse ecosystems in which the endangered species $P$. africana is found.

Classification results have accurately presented the various vegetation classes and defined the spatial extension of such classes. An interpretation and explanation of these vegetation classes is necessary in order to clearly frame the distribution of the medicinal plant $P$. africana on Bioko. P. africana occurs in varying quantities according to vegetation type, Vancutsem, et al., 2009. It must be stated directly that $P$. africana constitutes a major part of the climax montane forest of Bioko. This tree can be found in Araliaceae forests in great size and distribution forming up to $60 \%$ of the forest canopy in some areas (Hill, 1999). This species is also found in great numbers in secondary forests, which having been left to regenerate may soon be considered part of Bioko's Araliaceae forest, rather than secondary forest. P. africana should not be considered a secondary forest species on Bioko, but instead an indicator of maturity and successional age of these forests. P. africana occurs along with Schefflera sp., the arboreal species which typifies the Araliaceae type Afromontane forests of Bioko.

The distribution of Afromontane forests on Bioko is clearly due to a number of factors, particularly the oceanic cooling effect and monsoon phenomena which affect this island. Bioko provides a suitable habitat for $P$. africana, which has been associated with cooler temperatures (Hall, et al., 2000) and 
other species found on the highest mountains of continental Africa. The particular environmental conditions of Bioko do not only influence the distribution of this Afromontane species, but also other vegetation formations found on this island. A discussion of the vegetation classes derived from the supervised classifications of Bioko Landsat OLI-8 data will make the effects of these factors more evident, Song, et al., 2001.

\section{Conclusion}

The detection of individual species in tropical forests is a common objective, yet also a limitation when working with remotely sensed tropical forest data. Humid tropical forest types have low spectral separability in Landsat OLI-8 data due to highly textured reflectance patterns at the $30 \mathrm{~m}$ spatial resolution. Various methods of reducing spectral variation, low-pass spatial filtering and image segmentation exist. The Landsat image used in this study was not filtered before classification. Considering the relatively small surface area of Bioko (2017 $\mathrm{km}^{2}$ ), it was decided that local spectral variation was insignificant and explainable. Within the context of the Bioko montane classification, some areas which were represented by a mix of classified pixels were interpreted to be at a successional stage not specified by the supervised classification training areas. Secondly, the field work methodology was designed with the intention of applying field observations (systematic vegetation inventories as well as $P$. africana and other observations) to individual pixels for use during the supervised classification. Nonetheless, the ability to derive these tropical forest classes allows for greater use of classified imagery in conservation planning and future studies of Bioko. The supervised classification has produced an accurate classification of Bioko's vegetation types. Besides this, floristic and structural data recorded during field observations indicate differences between forest structures. These differences have been presented in the supervised classification of Afromontane vegetation. Results from the confusion matrix derived during the accuracy assessment may be attributed to factors which include methodological choices, and morphologic and structural characteristics among vegetation classes. It is quite important that the confusion matrix be examined not solely as a measure of the producer accuracy, but also in order to optimize the impression given to the user during analysis of the final thematic map. The errors of commission indicate similarities among vegetation classes which also elaborate the discussion of these vegetation types.

\section{References}

Boyd, D. S. and Duane, W. J. (2001) Exploring spatial and temporal variation in middle infrared reflectance (at $3.75 \mathrm{~mm}$ ) measured from the tropical forests of West Africa, International Journal of Remote Sensing, 22: 1861-1878.

Bussmann, R. (2006) Vegetation zonation and nomenclature of African Mountains. An overview, Lyonia, 11: 4166.

Cohen, J. (1960) A Coefficient of Agreement for Nominal Scales, Educational and Psychological Measurement, 20: 37-46.

Congalton, R. and Mead, R. (1983) A Quantitative Method to Test for Consistency and Correctness in Photointerpretation. Photogrammetric Engineering and Remote Sensing, 49 (1): 69-74.

Congalton, R. (1991) A Review of Assessing the Accuracy of Classification of Remote Sensed Data, Remote Sensing of Environment, 37: 35-46.

Cunningham, A. B. and Mbenkum, F. T. (1993) Sustainability of Harvesting Prunus Africana Bark in Cameroon, People and Plants Working Paper, 2. UNESCO, Paris.

Elhag, M., Psilovikos, A. and Sakellariou, M. (2013) Detection of land cover changes for water recourses management using remote sensing data over the Nile Delta region, Environment, Development and Sustainability, 15 (5): 1189-1204.

Fa, J. E. (1991) Conservacion de los ecosistemas de Guinea Ecuatorial, IUCN: Gland, Switzerland and Cambridge, UK. 
Foody, G. M. (2002) Status of land cover classification accuracy assessment, Remote Sensing of Environment, 80: 185-201.

Foody, G. M. and Hill, R. A. (1996) Classification of tropical forest classes from Landsat TM data, International Journal of remote Sensing, 17: 2353-2367.

Global Volcanism Program. (2005) Smithsonian Institution, http://www.volcano.si.edu.

Hall, J. B., O'Brien, E. M. and Sinclair, F. L. (2000) Prunus africana: a monograph. School of Agricultural and Forest Sciences Publication Number X. University of Wales, Bangor.

Hill R. A. (1999) Image segmentation for humid tropical forest classification in Landsat TM data, International Journal of Remote Sensing, 20: 10391044.

Jensen, J. (1996) Introductory Digital Image Processing: A Remote Sensing Perspective, Second Edition, Prentice Hall, Upper Saddle River, N.J., p. 305.

Juste, J. B. and Fa, J. E. (1994) Biodiversity conservation in the Gulf of Guinea islands: taking stock and preparing action, Biodiversity and Conservation, 3: $759-771$

Richards, J. (1993) Remote Sensing Digital Image Analysis: An Introduction. Second, Revised and Enlarged Edition. Springer-Verlag: New York.

Ricklefs, R. E. (1987) Community diversity: relative roles of local and regional processes, Science, 235: 167-171.

Salovaara, K. J., Thessler, S., Malik, R.N. and Tuomisto, H. (2005) Classification of Amazonian primary tain forest vegetation using Landsat ETM + satellite imagery, Remote Sensing of Environment, 97: 39-51.

Simons, A. J. and Leakey, R. R. B. (2004) Tree domestication in tropical agroforestry, Agroforestry Systems, 61:167-181.

Song, C., Woodcock, C., Seto, K., Lenney, M. and MaComber, S. (2001) Classification and change detection using Landsat TM data: When and how to correct atmospheric effects? Remote Sensing of Environment, 75: 230-244.

Sunderland, T. C. and Tako, C. T. (1999) The Exploitation of Prunus africana on the island of Bioko, Equatorial Guinea: A Report for the People and
Plants Initiative, WWF-Germany and the IUCN/SSC Medicinal Plant Specialist Group.

Thenkabail, P. S., Enclona, E. A., Ashton, M. S., Legg, C. and Jean De Dieu, M. (2004) Hyperion, IKONOS, ALI, and ETM+ sensors in the study of African rainforests, Remote Sensing of Environment, 90: 23 43.

Thenkabail, P. S., Hall, J., Lin, T., Ashton, M. S., Harris, D. and Enclona, E.A. (2003) Detecting Floristic Associations in a Mixed Species Central African Forest Using High Spatial and Spectral Resolution Satellite Images, International Journal of Applied Earth Observation and Geoinformation, 4: 255-270.

Thibaut Kaptué, A., De Jong, S., Roujean J., Favier, C. and Mering, C. (2011) Ecosystem mapping at the African continent scale using a hybrid clustering approach based on 1-km resolution multi-annual data from Spot/Vegetation, Remote Sensing of Environment, 115: 452-464

Toney, M., Stella, A., Ndam, N. and Blackmore, P. (2000) State of Knowledge Study on Prunus Africana (Hook.f) Kalkman. Report for the Regional Central African program for the environment, 68 .

Vancutsem, C., Pekel, J., Evrard, C., Malaisse, F. and Defourny, P. (2009) Mapping and characterizing the vegetation types of the Democratic Republic of Congo using SPOT time series, International Journal of Applied Earth and Geoinformation, 11: 62-76.

Vieira, I. C. G., Silva de Almeida, A., Davidson, E. A., Stone, T. A., Reis de Carvalho, C. J. and Guerrero, J. B. (2003) Classifying successional forests using Landsat spectral properties and ecological characteristics in Eastern Amazonia, Remote Sensing of Environmental, pp: 470-481.

White, F. (1983) The vegetation of Africa, a descriptive memoir to accompany the UNESCO/AETFAT/UNSO Vegetation Map of Africa (3 Plates, Northwestern Africa, Northeastern Africa, and Southern Africa, 1:5,000,000). UNESCO: Paris.

Zafra-Calvo, N., Cerro, R., Fuller, T., Lobo, J., Rodríguez, M. and Sarkar, S. (2010) Prioritizing areas for conservation and vegetation restoration in postagricultural landscapes: A Biosphere Reserve plan for Bioko, Equatorial Guinea, Biological Conservation, 143: 787-794. 


\section{رسم خرائط الغابات الاستوائية في جزيرة بيوكو باستخدام تقنيات الاستشعار عن بعد}

\section{محمد الحاج}

قسم علوم وإدارة موارد المباه، كلية الأرصاد والبيئة وزراعة المناطق الجافة، جامعة الملك عبدالعزيز،

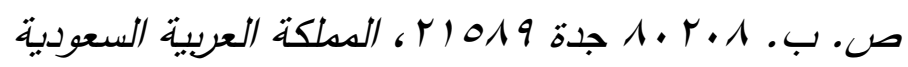

melhag@kau.edu.sa

الستخلص. تتطلب الإدارة المستدامة للغابات الاستوائية إلى خرائط الغطاء النباتي الملائمة. وتقتيات

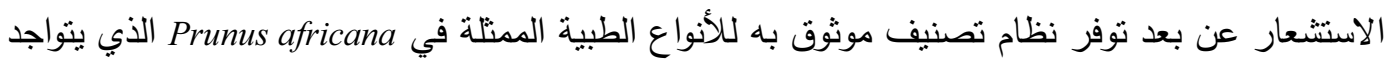
في جزيرة بيوكو - غينيا- الاستوائية.

تعتمد الإدارة المستخامة أساسًا على القياس الكمي لمجموعات Prunus africana لتحديد حجم التجارة المستدامة. نفذت تقنيات تصنيف الصور الفضائية غير الخاضعة للرقابة والخاضعة للرقابة على لاندسات (أرض التشغيلي تصوير -( ) لإنتاج خرائط موضوعية لـ OLI-8

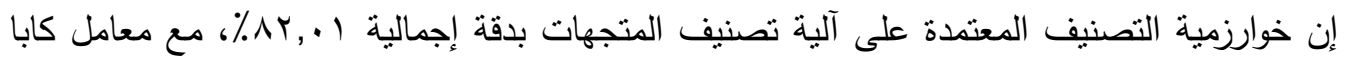

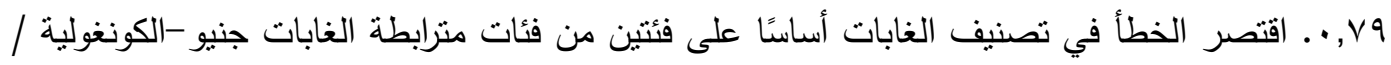
وإفرومونتانا في الطبقات المنخفضة من الغابات. لذلك تم بإضافة قاعدة إضافية إلى حكم قرار التصنيف

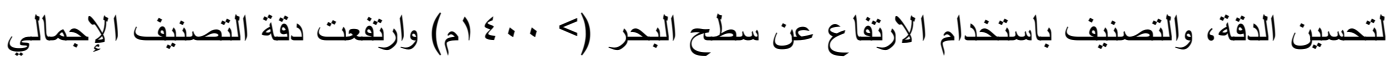

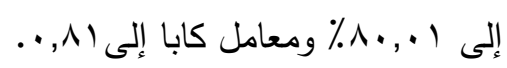

تم جمع البيانات الأرضية من تسعة مقاطع عرضية لكلا من Srunus africana وجنس Schefflera. ويغلب اثثين من الأنواع الثجرية الموجودة في الغابات بيوكو على باقي الأصناف الموجودة. إن خرائط

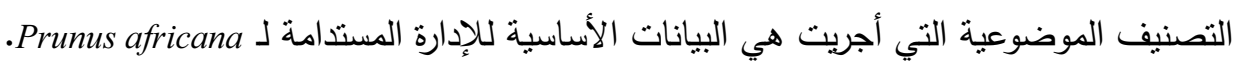
قد تكون هذه النتائج أيضًا ذات قيمة لمختلف الدراسات المستقبلية التي تشتمل على الاختلافات البيئية من Prunus africana في جزيرة بيوكو. هن المان. الكلمات الدالة : غابات الإفرومونتانا، لانسات - A، إنتاج الأخشاب، غابات استوائية، Prunus Africana. 
